\title{
Tuberous sclerosis: a large family with no history of seizures or mental retardation
}

\author{
A E FRYER, J P OSBORNE, R TAN, AND D C SIGGERS \\ From the Departments of Paediatrics, Dermatology, and Genetics, Royal United Hospital, Bath BA1 $3 N G$.
}

SUMMARY A family is reported where tuberous sclerosis has probably affected five generations, but where none of the members has been mentally retarded and there is no history of seizures.

Tuberous sclerosis is a complex disorder, characterised by multiple hamartoma formation. It behaves as a Mendelian dominant, but is very variable in expression. Large multigeneration families with tuberous sclerosis are rare because many cases appear to be new mutations, many patients are mentally handicapped and are less likely to reproduce, and families with one handicapped child may limit their family size. We present a family where five generations appear to have been affected, but where none of the members has been mentally retarded and there has been no history of seizures.

\section{Case reports}

Patient IV.4 (figure) presented to the Dermatology Clinic in 1983 at 31 years of age. He had facial angiofibromas and periungual fibromas. These had both been present since teenage years. His facial lesions were causing considerable bleeding when shaving and his ungual fibromas had grown and were catching on the bed sheets at night. He was of normal intelligence, working for his unaffected brother (IV.3) as a building contractor. He has no history of seizures. When attending the clinic, he was accompanied by several other members of his family, some of whom also had signs of tuberous sclerosis. The findings are summarised in the table. No members of the family, whether affected or not, had a history of seizures and all were of normal intelligence, having learnt to read and write and being employed in skilled or unskilled jobs. The two affected children (V.2 and V.3) are at normal school, making satisfactory progress.

In generation II (figure), three members of the family were known to have tuberous sclerosis. All of them had facial angiofibromas. II.1 and II.4 were both council employees. Medical records are scanty with regard to these two members, though II. 2 still has hospital notes relating to an admission at 31 years of age to a psychiatric unit (1907 to 1911) with a depressive illness. Her admission notes record that she had no history of epilepsy and that she was able to read and write. Her occupation was recorded as 'gloving and housework'. During her four years admission there were no recorded seizures.

Little is known about generation I. It is not clear which parent might have carried the gene. I.1 died in 1932 at 84 years of age. He was a labourer. It is thought by his grandson (III.1) that he did not have any facial lesions. I.2 died suddenly in 1912 at 64 years of age. Neither death certificate was helpful with regard to the diagnosis of tuberous sclerosis.

\section{Discussion}

Seizures and mental retardation are common neurological manifestations of tuberous sclerosis. Seizures have been reported in $80 \%$ of childhood cases, ${ }^{1}$ though as infrequently as $25 \%$ in a series from a largely adult population. ${ }^{2}$ Mental retardation is

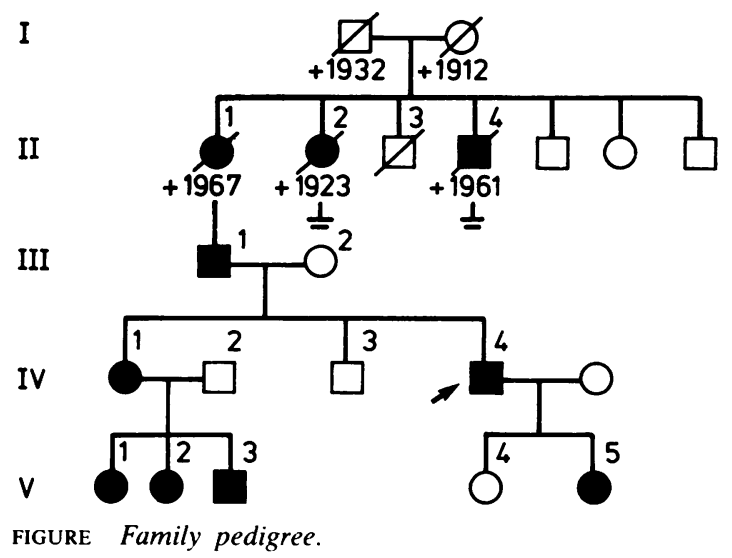


TABLE Clinical features of family members.

\begin{tabular}{|c|c|c|c|c|c|c|}
\hline Patient & Age (y) & Facial angiofibromas & Ungual fibromas & Hypomelanic macules & Shagreen putch & $C T s$ \\
\hline IV.4 & 34 & + & + & N/K & - & N/K \\
\hline IV.1 & 48 & + & + & $\mathrm{N} / \mathrm{K}$ & - & $\mathrm{N} / \mathrm{K}$ \\
\hline V.1 & 20 & + & $-*$ & + & - & + \\
\hline V. 2 & 12 & + & + & $\mathrm{N} / \mathrm{K}$ & + & $\mathrm{N} / \mathrm{K}$ \\
\hline V. 3 & 9 & + & $-{ }^{*}$ & + & - & N/K \\
\hline III. 1 & 74 & + & + & $\mathrm{N} / \mathrm{K}$ & - & $\mathrm{N} / \mathrm{K}$ \\
\hline
\end{tabular}

* Both these patients had ridged nails suggesting clinically hidden fibromas of the nail bed.

$\mathrm{N} / \mathrm{K}=$ not known.

reported in 50 to $60 \%$ of patients. ${ }^{3}$ This family would appear to be the only large one reported where these neurological manifestations are absent. Mild cases, with skin features alone, could be commoner than is thought and may not be brought to medical attention. If these patients do present to general practitioners, they may not be referred to a dermatologist for a specific diagnosis if the symptoms are minor. Even if a specific diagnosis is made, the genetic implications are not always realised and hence other members of the family who may have the disease in a mild form may not be examined.

The risk to a subsequent generation of neurological manifestations is difficult to determine in this family. The remarkable variability within other families with tuberous sclerosis indicates that the absence of neurological symptoms in this family may well be fortuitous. This is difficult for the family to accept. It is interesting to speculate that this family has a high threshold for seizures and that this mitigates against the development of mental retardation. This is a hypothesis that needs testing: if it is true, the early successful treatment of seizures in tuberous sclerosis might prevent the development of mental retardation. Mental retardation without seizures is very rare in this condition.

AEF is supported by a grant from the Tuberous Sclerosis Association of Great Britain and the Bath Unit for Research into Paediatrics. Cow and Gates Ltd offered further financial support.

\section{References}

1 Gomez MR. Clinical experience at Mayo Clinic. In: Gomez MR, ed. Tuberous sclerosis. New York: Raven Press, 1979 11-26.

2 Cornell $\mathbf{J}$. Tuberous sclerosis-clinical manifestations and gẹ tic implications. $S$ Afr Med J 1983;63:966-8.

${ }^{3}$ Hunt A, Lindenbaum RH. Tuberous sclerosis: a new estimatero prevalence within the Oxford region. J Med Genet 1984;21 272-7.

Correspondence and requests for reprints to Dr J B Osborne, Royal United Hospital, Combe Park $\overrightarrow{0}$ Bath BA1 3NG. 